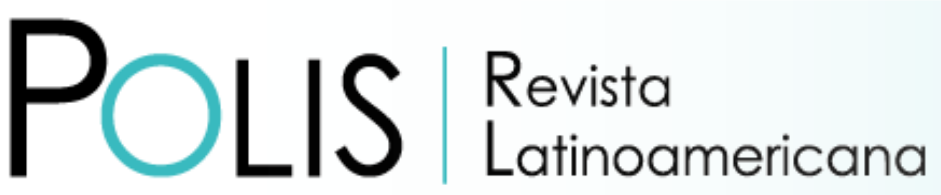

V20 | N60 | 2021

DOI: $10.32735 /$ S0718-6568/2021-N60-1654

\title{
Bordando narrativas de resistencia: Prácticas y experiencias de mujeres mayores activistas
}

\author{
Nicole Mazzucchelli \\ Pontificia Universidad Católica de Valparaíso, Valparaíso, Chile \\ Universidad Autónoma de Barcelona, Barcelona, España \\ Email: nicole.mazzucchelli@pucv.cl \\ María Isabel Reyes-Espejo \\ Pontificia Universidad Católica de Valparaíso, Valparaíso, Chile \\ Email: maria.reyes@pucv.cl

\section{Lupicinio Íñiguez-Rueda} \\ Universidad Autónoma de Barcelona, Barcelona, España \\ Email: Iupicinio.iniguez@uab.cat
}

Recibido: 31.05.2021 | Aceptado: 02.08.2021

\begin{abstract}
Resumen: Los modelos convencionales de vejez sitúan a las mujeres mayores en peores condiciones que los hombres, describiéndolas como un grupo homogéneo y desatendiendo sus potencialidades y recursos. Este trabajo aborda las experiencias y prácticas de resistencia que mujeres mayores activistas de la agrupación Bordadoras por la Memoria de Chile, despliegan en su vida cotidiana en el contexto de la pandemia por Covid19. En afinidad con la gerontología feminista y los saberes situados, el uso de la metodología de las producciones narrativas grupales permitió profundizar en la agencia que las mujeres activistas emplean para disputar la vejez convencional. Los resultados muestran que su experiencia de envejecer desde la acción política, les permite resistir al confinamiento sanitario, innovar en sus rutinas y formas de comunicación, así como crear nuevas estrategias para la resolución de problemas. Desde este lugar cuestionan los mandatos de normatividad en la vejez y critican reflexivamente la acción pública e institucional dirigida a las personas mayores en Chile. Se concluye que el saber producido por las mujeres permite tensionar y disputar posiciones, transgrediendo la representación de la vejez que las ubica en los márgenes, visibilizando su agencia y contribuciones sociales.
\end{abstract}

Palabras Clave: Gerontología feminista; vejez; agencia; producciones narrativas. 


\title{
Embroidering Narratives of Resistance: Practices and Experiences of Older Female Activists
}

\begin{abstract}
Conventional models of old age place older women in worse conditions than men, describing them as a homogeneous group and neglecting their potential and resources. This paper addresses the experiences and practices of resistance that older women activists from the group Bordadoras por la Memoria de Chile (Embroiderers for Memory of Chile) deploy in their daily lives in the context of the Covid19 pandemic. In affinity with feminist gerontology and situated knowledge, the use of the methodology of group narrative productions allowed us to delve deeper into the strategies that women activists employ to contest conventional old age. The results show that their experience of ageing through political action allows them to resist health confinement, to innovate in their routines and forms of communication, and to create new strategies for problem solving. From this place, they question the mandates of normativity in old age and reflexively criticise public and institutional action aimed at the elderly in Chile. It is concluded that the knowledge produced by women tensions and disputes positions, transgressing representations of old age that marginalizes them, visualizing their agency and social contributions.
\end{abstract}

Keywords: Feminist gerontology; old age; agency; narrative productions.

\section{Bordando narrativas de resistência: práticas e experiências de mulheres idosas ativistas}

Resumo: Os modelos convencionais de velhice colocam as mulheres mais velhas em piores condições que os homens, descrevendo-as como um grupo homogêneo e negligenciando seu potencial e recursos. Este artigo aborda as experiências e práticas de resistência que as mulheres mais velhas ativistas do grupo Bordadoras por la Memoria de Chile (Bordadeiras pela Memória do Chile) empregam em sua vida cotidiana no contexto da pandemia de Covid 19. Em afinidade com a gerontologia feminista e o conhecimento situado, o uso da metodologia das produções narrativas de grupo nos permitiu aprofundar as estratégias que as ativistas feministas empregam para contestar a velhice convencional. Os resultados mostram que sua experiência de envelhecimento através da ação política lhes permite resistir ao confinamento sanitário, inovar em suas rotinas e formas de comunicação, e criar novas estratégias para a solução de problemas. A partir deste lugar, questionam os mandatos de normatividade na velhice e criticam reflexivamente a ação pública e institucional voltada para os idosos no Chile. Conclui-se que o conhecimento produzido pelas mulheres permite a tensão e a disputa de posições, transgredindo a representação da velhice que as coloca à margem, tornando visível sua agência e suas contribuições sociais.

Palavras-chave: Gerontologia feminista; envelhecimento; ativismo; produções narrativas.

\section{Como citar este artículo:}

Mazzucchelli, N., Reyes-Espejo, M. y Íñiguez-Rueda, I. (2021). Bordando narrativas de resistencia: Prácticas y experiencias de mujeres mayores activistas. Polis Revista Latinoamericana, 20 (60), 9-27. doi: http://dx.doi.org/10.32735/S0718-6568/2021-N60-1654 


\section{Introducción}

El envejecimiento de la población mayor a nivel mundial y la extensión de la esperanza de vida, es considerado un indicador de éxito-progreso en las sociedades modernas (Love, 2018). En Latinoamérica este fenómeno se proyecta de forma más acelerada, aunque con diferencias abismantes entre sus países, considerando: la expectativa de vida, acceso a la salud, seguridad social y efectivo goce de derechos (CEPAL, 2019). Este escenario da cuenta de contextos desiguales para el abordaje de esta problemática, viéndose amenazado por la ausencia de un soporte institucional que permita sostener el amplio número de personas mayores que habitan en condiciones de desigualdad (Huenchuán, 2018). Particularmente, éstas afectan a las mujeres, ya que el envejecimiento poblacional está caracterizado por su feminización (CEPAL, 2019).

Esta precariedad y vulnerabilidad, ha quedando en evidencia en el contexto sanitario de pandemia por Covid-19 (Pinazo-Hernandis, 2020). Tempranamente, la Organización Mundial de la Salud (OMS, 2020) indicó la importancia de proteger a este grupo, señalando la necesidad de incorporar medidas que garantizaran su participación y autonomía, e incluyeran el género como un factor estructural en el impacto de la crisis. No obstante, pese a las advertencias, las personas mayores y, en particular las mujeres, no han recibido la atención y el soporte institucional que garantice la prevención del contagio y el pleno ejercicio de sus derechos. Así, recientes estudios reportan que, al ubicar a éstas como grupo de riesgo, aumentan los estereotipos edadistas, desconociendo sus capacidades y autonomía (Dourado, 2020).

En este contexto de vulnerabilidad en la vejez, la participación social es considerada fundamental para envejecer con calidad de vida y bienestar $y$, desde esta perspectiva, es valorada tanto en términos de su integración a la sociedad como por las oportunidades de actuación asociativa que tienen las personas mayores para realizar contribuciones a nivel político y social (Raymond, Grenier y Hanley, 2014). El abordaje de la participación en la vejez ha transitado en los últimos años desde un discurso focalizado en la protección de las personas mayores consideradas como vulnerables, hacia un reconocimiento progresivo de sus capacidades, poniendo en valor su agencia y contribución. Así, frente a nuevos escenarios de organización social, el activismo de personas mayores que revindican sus derechos ha adquirido un notorio protagonismo (Chazan, 2016).

En Chile, la revuelta social del 18 de octubre de 2019 reveló una serie de opresiones y desigualdades acumuladas en el contexto postdictatorial, siendo una de éstas, las precarias condiciones en la que se envejece en Chile (Akram, 2020). Las personas mayores salieron a las calles, exponiendo sus demandas, posicionándose como sujetos que continúan disputando su ciudadanía y manifiestan su descontento con el modelo económico-social (Herrera, Fernández y Rojas, 2020). En el contexto de pandemia, estas demandas se acrecentaron, acentuando las condiciones de desigualdad de las personas mayores, y ubicándolas entre los grupos de mayor riesgo (Osorio, Jorquera y Araya, 2021). Así, se dispuso una serie 
de medidas sanitarias focalizadas en la población mayor como: la obligatoriedad de la cuarentena para las personas sobre los 75 años, la prohibición de visitas de familiares a los establecimientos de larga estadía, el cierre de centros y espacios de recreación y encuentro comunitario, entre otras (MINSAL, 2020).

Las personas mayores desplegaron una serie de estrategias para afrontar la crisis sanitaria y adaptarse a sus restricciones, sorteando estas dificultades (Osorio, et. al, 2021). Igualmente, instituciones y organizaciones sociales-comunitarias, han promovido iniciativas dirigidas principalmente a este grupo, en pos del resguardo de sus derechos e inclusión social. A través de actividades de difusión-recreación, como conversatorios, talleres, apoyo tecnológico, entre otras, se ha favorecido la participación de las personas mayores, su vinculación, el intercambio intergeneracional y el debate de situaciones específicas que los aquejan. Una de estas iniciativas fue el "Diario íntimo de Chile" que recogió 387 testimonios de personas mayores, que, a través de sus escritos, expusieron reflexiones respecto a la vejez y el covid19, desde sus experiencias cotidianas (Diario íntimo, 2020).

No obstante, estas acciones desarrolladas durante la pandemia, lo cierto es que en Chile -como en otras regiones- no se favorece la participación de las personas mayores. La inexistencia de recursos para habitar la vejez de forma digna ha evidenciado cómo los problemas específicos que aquejan a este grupo han sido sistemáticamente desatendidos por parte de los organismos internacionales (CEPAL, 2019). En este escenario, las representaciones de la vejez se han visto fuertemente permeadas por los estereotipos negativos, mostrando a las personas mayores como enfermas, pasivas y dependientes, desvalorizando sus contribuciones políticas-sociales (Ithurburu, 2014). Considerando que los modelos convencionales de envejecimiento representan a la población mayor de manera homogénea y universal, las mujeres mayores han sido fuertemente invisibilizadas (Yuni, 2019). Se han ignorado dificultades específicas que impactan en su bienestar, como la continuidad del trabajo remunerado después de la jubilación y el trabajo de cuidados que éstas realizan (Gonzálvez y Lube, 2020). Su estigmatización se ha visto doblemente acentuada como efecto de su invisibilización en la investigación académica, en los medios de comunicación y por su falta de consideración en los espacios de poder (Freixas, 2002; 2008). En este sentido, el activismo y la organización política de las mujeres mayores ha sido escasamente investigada. Frente al predominio del estudio de trayectorias individuales, se ha restado valor al carácter relacional y psicosocial de la experiencia de envejecer (Chazan, 2016; Wray, 2004), invisibilizando sus recursos (Ramos, 2017) y prestando más atención a sus contribuciones pasadas que a sus reivindicaciones presentes (Chazan, 2016).

En este artículo, nos proponemos describir las experiencias y prácticas de resistencia de mujeres mayores activistas de la Colectiva Bordadoras por la Memoria, buscando contribuir a la comprensión de su agencia política en la vejez. Así, desde una perspectiva crítica y feminista, visibilizamos sus acciones de resistencia en el contexto de la crisis sanitaria por Covid 19, mostrando cómo desde sus narrativas se disputan otras versiones de vejez, ubicándolas como activistas referentes para sus comunidades y territorios. 


\section{Agencia y vejez: Apuntes en clave feminista}

La instalación de las mujeres en la categoría de población mayor ha contribuido a que ellas desaparezcan y no se integre, ni represente, la diferencia. Los cursos de vida de las mujeres, en general, son incorporados desde un patrón rígido, lineal y uniforme en su desarroIlo, que promueve como meta, alcanzar un modelo de vejez ideal (Sampedro, 2015). Este fenómeno, denominado por Celia Amorós (2001) como de "indiscernibilidad", se refiere a la generalización de las mujeres y su tratamiento como un grupo homogéneo, sin diferencias, o especificidades, junto con no ser consideradas sujetos políticos. Desde este lugar, las mujeres se configuran en un "sujeto subalterno" para el pensamiento social" (Gonzálvez y Lube, 2020, p .6). Esta situación repercute en que se normalicen ciertos cursos de vida, se ignoren sus trayectorias y experiencias y continúen ubicándose en los márgenes del debate científico, público y cultural. En el caso de las mujeres mayores, esta omisión impide apreciar cómo a través del ejercicio de su agencia éstas pueden desarrollar estrategias que les permiten confrontar situaciones de opresión en torno al género y edad (Charpentier y Quéniart, 2017).

Desde los modelos convencionales de vejez, las conceptualizaciones de "empoderamiento, agencia y participación" son utilizadas para describir, de forma análoga, las condiciones saludables de esta etapa vital; pero, al omitir sus especificidades y características, se resta valor al impacto diferencial que pueden presentar en el análisis del envejecimiento. La agencia, en particular, refiere a las capacidades adaptativas que las personas, en términos masculinos, desarrollan en esta etapa, como indicadores de éxito o fracaso, autosuficiencia y autonomía individual. Con ello, se ha desestimado el interés por abordar su expresión en contextos grupales y asociativos, tendiendo a considerar la agencia como una práctica personal y no relacional (Wray, 2004; 2007). Así, se ha dejado de prestar atención al hecho de que la agencia en hombres y mujeres podría expresarse de forma diferente en la vejez, asociada a sus transiciones vitales (Chazan, 2016). En este sentido, la comprensión de la agencia de las mujeres mayores suele limitarse al reconocimiento de sus beneficios individuales o a su aporte recreativo, sin atender a su carácter reivindicativo y político (Zubero, 2018). Asimismo, la dimensión política se ha reducido al actuar público-tradicional, desatendiendo al hecho de que la agencia de las mujeres, por lo general, se desarrolla desde y en sus contextos cotidianos (Wray, 2004).

Lejos de esta visión, en este estudio comprenderemos la agencia como la posibilidad de las mujeres de actuar modificando los contextos y reglas que las preceden y constituyen; por tanto, más que una propiedad individual, es entendida como un producto de relaciones y responsabilidades compartidas (Ema, 2004) y en articulación entre entidades híbridas diversas (Haraway, 1995). La agencia de las mujeres mayores se constituye en una mediación que reproduce, mantiene y/o transforma la vida social. Desde una perspectiva feminista, se entiende como práctica de "resistencia" a la victimización (Troncoso y Piper, 2015) anclada en la oposición activa que las mujeres despliegan, de forma planificada o fragmentada, respecto a la subordinación y domesticación del sistema dominante (Contreras, Guajardo 
y Zarzuri, 2005). De esta manera, los contextos culturales específicos en los que éstas desarrollan su agencia actuarán como escenarios de posibilidad para las construcciones alternativas que las mujeres realizan desde los márgenes (Ema, 2004).

Desde antaño, las mujeres mayores en Chile cuentan con trayectorias vinculadas a la acción política en sus contextos comunitarios, propiciando la organización social de base y el reconocimiento en el espacio público, frecuentemente dominados por los hombres (Valdés, 1986). En este escenario, comparten una historia social y cultural como generación que las impacta distintivamente. Esta generación, denominada "baby boom", es caracterizada por experimentar profundos cambios sociales al vivenciar el quiebre de paradigmas políticos clásicos, los movimientos sociales de los 70', junto con ser ésta la protagonista de la revolución cultural (Moya, 2013). También fueron ellas quienes lideraron la defensa a los derechos humanos y la resistencia a las dictaduras del Cono Sur (Sapriza, 2009). En este sentido, su agencia debe ser comprendida considerando el contexto histórico-social en el que se inscriben sus biografías.

Actualmente, un alto porcentaje de mujeres mayores en Chile participa de algún tipo de organización social y/o comunitaria (alcanzando un 43,9\%, según la Encuesta UC Calidad de vida en la vejez, 2020). Uno de los focos examinados en torno a la participación en la vejez, ha sido el de los cuidados. Para Constanza Gómez-Rubio (2019), la participación en organizaciones para proveer cuidados comunitarios se transforma en una práctica de resistencia frente a la desprotección social. En afinidad, otras autoras reportan la experiencia de participación en clubes de adultas mayores a nivel rural (Caro, 2017) y urbano (Gonzálvez, Lube, Ramírez y Cano, 2019), valorando estos espacios por el bienestar que emerge a partir de la construcción de relaciones al interior de la organización. No obstante, estos trabajos y los aportes sugeridos, se observa un vacío en la indagación en torno a la acción política de las mujeres en su vejez. Por ello, resulta un desafío, poder explorar los diferentes modos en los que despliegan su agencia, renuevan sus prácticas y continúan resistiendo al orden social.

\section{El método: Producciones narrativas colectivas}

En esta investigación, proponemos un andamiaje teórico-metodológico entre los conocimientos situados y las producciones narrativas (en adelante PN) como construcciones colectivas a múltiples voces (Balasch y Montenegro, 2003). Desde la producción de saberes situados como un conocimiento posicionado, parcial y encarnado (Haraway, 1995), desnaturalizamos ciertos supuestos epistemológicos como la incuestionable racionalidad científica, que ha legitimado discursos hegemónicos en el campo de la edad, asociados al éxito en la vejez y que ha caracterizado a las mujeres aludiendo a cualidades esencialistas de feminidad, despojándolas de su agencia política. 
Desde una visión socioconstruccionista, reconocemos que los saberes situados permiten una comprensión en diálogo y compleja de la realidad. Así, nos nutrimos de las narrativas que articulan la dimensión cultural y personal como constructoras de significado en la vida cotidiana (Gergen y Gergen 1983). De esta forma, las PN consideran la elaboración conjunta de un texto que se construye en diferentes encuentros entre participantes e investigadores/as (Balasch y Montenegro, 2003). A través de las PN colectivas, creamos un "texto híbrido" y organizado que recoge las diversas posiciones y argumentos de las participantes, permitiendo su re-elaboración, expansión, edición, etc., hasta que la narrativa fue validada por sus propias protagonistas.

Desde este marco, no se recogen las palabras desde su textualidad ("lo dicho"), sino que se recupera la forma en que las participantes quieren transmitir su visión (Balasch y Montenegro, 2003). Así, las PN ofrecen una comprensión del relato, más allá de su registro, como una narrativa encarnada de construcción conjunta, que reconoce la agencia de las mujeres mayores y cómo resignifican su experiencia desde su posición material y semiótica a la vez que construyen su realidad. Las narrativas producidas en conjunto son consideradas una visión y saber válido en torno a la temática explorada (Schöngut y Pujol, 2015). Éstas no persiguen representar rasgos esenciales de los sujetos que hablan, ni describir su posición o experiencia de forma exhaustiva (Martínez y Montenegro 2010). Su interés está en "difractar", en ampliar comprensiones, sobre los fenómenos diversificando y complejizando los discursos dominantes (Haraway 1999/1992). De este modo, no existe un trabajo de "análisis" posterior a su producción. Se trabaja desde ellas y no sobre ellas (Martínez-Guzmán y Montenegro, 2010), implicando una interpretación situada constituida desde las propias conexiones producidas en el proceso y acto de investigar (Balasch y Montenegro, 2003). La investigación, aprobada por el Comité de Ética y Bioseguridad de la Universidad de afiliación de la primera autora, fue desarrollada durante los meses de marzo del año 2020, hasta marzo del año 2021, en la ciudad-puerto de Valparaíso, Chile. Trabajamos con 6 mujeres mayores entre 64 y 75 años, que conforman la agrupación Colectiva Bordadoras por la Memoria'. Este grupo, se reúne de forma periódica en el Centro Cultural de la ex Cárcel en Valparaíso, desde el año 2016. Comparten el interés por la justicia social, los Derechos Humanos y la mantención de la memoria; para que los hechos ocurridos en la dictadura cívico-militar de Pinochet, no se olviden y puedan ser aprendizajes para las generaciones venideras. Entre sus principales acciones políticas se encuentra el bordar. A través de sus obras/bordados recuerdan colectivamente, expresan posicionamientos, denuncias y continúan su lucha por la memoria social.

Adaptamos el diseño metodológico al escenario de contingencia por Covid-19. Esto implicó sumergirnos en las potencialidades de los diseños virtuales, ajustando las estrategias de producción de información, en sus formas y usos a un contexto remoto. En una primera fase, realizamos entrevistas biográficas a 6 integrantes de la agrupación, lo que promovió el de-

1 La Colectiva se inspira en la artesanía comunitaria de arpillera realizada por mujeres, en el contexto de la dictadura militar en Chile, como un modo de denuncia ante la represión. La agrupación, en honor a estas mujeres y sus reivindicaciones, pero en un esfuerzo de distinción, eligen la técnica del bordado como práctica política de su activismo. 
sarrollo de vínculos, afectos y la ubicación de ciertos ejes a dialogar en el trabajo colectivo. En una segunda fase nos reunimos para la elaboración conjunta de las PN, realizando un total de cuatro encuentros grupales virtuales para co-construir un relato híbrido. En cada sesión iniciamos la conversación, haciendo uso de imágenes y/o videos con el propósito de provocar y despertar la reflexión de ciertas temáticas en la interacción con los otro/as (Corredor y Íñiguez, 2016). El material utilizado incluía referencias a la población mayor de carácter sexista-viejista o reflejaban los discursos oficiales del Servicio Nacional de Personas Mayores (SENAMA) con relación a la política de envejecimiento positivo para Chile. Estos recursos facilitaron la generación de diálogos y favorecieron el tratamiento de diferentes temas que fueron emergiendo, también, de manera espontánea. Cada sesión tuvo una duración promedio de 2,5 horas.

En la primera sesión, discutimos en torno a un video del programa Adulto mejor ${ }^{2} y$, posteriormente, el diálogo se desarrolló en torno a las preguntas: ¿̇cómo representan la vejez? y żqué significados le otorgan? También se indagó en torno a su valoración del orden político-social y el contexto de envejecer en Chile. A partir de lo conversado, elaboramos un primer texto que recogía la discusión y sobre el cual trabajamos en las tres sesiones siguientes, discutiendo y re-editando las textualizaciones producidas. En las dos primeras sesiones, participaron todas las integrantes de la colectiva, y en las otras dos sesiones se ausentó una integrante cada vez. No obstante, ellas enviaron sus aportes y comentarios por escrito, solicitando se incluyesen en el debate grupal. Por consiguiente, desde la propuesta de PN, promovimos espacios de agencia y resistencia colectiva entre las mujeres mayores, ante un contexto social altamente edadista y excluyente con éstas (Freixas, 2008).

\section{Bordando narrativas de resistencia}

A partir del ejercicio del arte de bordar, los resultados que presentamos a continuación han sido organizados en términos dialógicos, intentando visibilizar figurativamente el proceso de construcción de la PN colectiva elaborada en conjunto con las integrantes de la agrupación Bordadoras por la Memoria. Organizamos los hilos discursivos de la PN colectiva-que refieren a la agencia y resistencia de estas mujeres frente al contexto de pandemia-divididos en tres ejes: 1) Tensionar la vejez hegemónica, 2) Resistir a la cotidianeidad pandémica y 3) Producir más vejeces activistas. Así, los diálogos que configuran este bordado articulan saberes propuestos en la PN y distintos aportes teóricos que permiten complejizar la comprensión de la vejez.

\section{Tensionar la vejez hegemónica}

La vejez es considerada la última etapa del ciclo vital de las personas, existiendo una serie de representaciones que la vinculan con signos de deterioro y dependencia (Villar y Serrat, 2015). Esta descripción ofrece una lectura decreciente, desde un enfoque androcéntrico,

2 Disponible en: https://www.youtube.com/watch?v=jg69uAcdzlc 
rígido y lineal que promueve la mantención de una mirada negativa y catastrófica del ser viejo/a (Sacramento, 2015). Esta caracterización ha asignando a cada edad determinados roles sociales; sin embargo, para las Bordadoras estas expresiones solo adquieren significado con la llegada de la pandemia:

"Cuando pensamos en la vejez, vemos que esta llegó de un sopetón, y decimos jnos llegó el viejazo!, jnos llegó de una! (...) llevábamos vidas muy activas, pero llegó la pandemia y todo se vino abajo (...) La pandemia se constituyó en un hito que aceleró el sentirnos mayores, pero también que ha deteriorado nuestra salud, a nivel físico y emocional. El no poder establecer relaciones cara a cara, y el compartir presencialmente nos ha afectado sintiéndonos frágiles y vulnerables (...) la pandemia nos enfrentó con la vejez (...) Bordadoras, 2021, p.1-3).

La disputa de la edad cronológica y su correspondencia con el ciclo vital se revela en la experiencia de reclusión compartida que es impuesta desde el contexto socio-sanitario. Las vivencias de la vejez, en este sentido, no se ven normalizadas por experiencias de enfermedad o malestar percibido, mostrándose también ajenas a expresiones subjetivas vinculadas con la edad. Así, el "viejazo" se les impone como una comprensión que interrumpe en sus vidas "un hito", señalando un quiebre entre sus experiencias "antes y después" de la pandemia. La reflexión avanza considerando la vejez como una etapa donde se vivencian cambios profundos a nivel físico y emocional-mental que deben ser asumidos como un proceso natural, que es parte de la vida. En este contexto, el desarrollo de procesos subjetivos y la revisión de sus propias experiencias se configuran como prácticas de resistencia y autocuidado, que se desmarcan de conceptualizaciones rígidas enfocadas en el deterioro y la patologización como únicas cualidades. Del mismo modo, extienden una invitación a resignificar la vejez desde un experienciar "encarnado" que permite dotar nuevos significados y sentidos a la comprensión de la vida:

"Algunas de nosotras describimos la vejez más desde lo físico, con algunas molestias corporales, dolores articulares o dificultades para mantener el ritmo que antes llevábamos (...) la vejez es un momento de profundos cambios. Tienes que vivirla para poder entender y significar lo que implica. Siendo más jóvenes no se logra comprender (...) consideramos que en la medida que continuamos siendo activas, ocupándonos por mantener una buena salud, podemos enfrentar de mejor manera esta etapa (...) es importante aceptar los cambios físicos y emocionales de esta etapa como parte de un proceso natural, de la vida misma" (Bordadoras, 2021, p.1-3).

Hace décadas, algunas pensadoras feministas advertían que hacerse mayor implicaba un significado cultural diferente entre hombres y mujeres; situando a estas últimas en un lugar de desventaja frente a la madurez alcanzada por los hombres $y$, donde el envejecer, supone un estrechamiento de sus relaciones sociales y una reducción de sus posibilidades de situarse desde el mundo público (Datan, 1989; Heilbrun 1988/1994). Sin embargo, para las Bordadoras la experiencia de envejecer no se reduce a la construcción de carencia, sino que -por el contrario- se actualiza en la ampliación de sus límites y los modos de vida explorados en esta etapa," (...)al ser mayores comenzó a importarnos menos la opinión del resto (...) menos responsabilidades hacia los otros, y mas tiempo para realizar lo que a nosotras nos hace sentido ¡Hay que pensar que entre los 60 y algo y los 70 y algo, son los nuevos 60 !(Bordadoras, 2021, p.2). 
Lo anterior coincide con el planteamiento de algunas autoras, que describen la vejez como una etapa en la que se promueven procesos de emancipación y empoderamiento que previamente las mujeres no habían experimentado (Ramos, 2017). Así, su declamación json los nuevos 60!, se constituye en una suerte de arenga que amplía su mirada sobre el uso del tiempo en el curso vital, pues ahora sí sienten que tienen libertad. En afinidad con lo planteado, Carolyn Heilbrun (1988/1994) expone que las mujeres que deseen vivir en su vejez fuera de las prescripciones del patriarcado tienden a desarrollar estrategias para confrontar las imposiciones sociales. En este sentido, las Bordadoras indican que la experiencia de ser mayores les ha enseñado a aprovechar cada momento y disfrutarlo. Así, considerando el contexto actual de pandemia, su agencia individual se ve fortalecida, principalmente, porque han dispuesto de más tiempo para ellas, permitiéndoles, reflexionar, pensar en ellas mismas, ocuparse de su salud y prepararse física y emocionalmente, para enfrentar la vejez más avanzada en mejores condiciones. (Bordadoras, 2021).

A través del proceso narrativo, se da cuenta que vivir la pandemia desde la vejez, ha significado poder encontrarse consigo mismas, pero también y desde su participación en el colectivo, la categoría mujeres las ha conectado con la posibilidad de rescatar lo bello de cada persona, el respetarse y acogerse en su pluralidad. De esta manera, se aprecia cómo ponen en valor el concepto de sororidad, entendido como un proceso de apoyo e intercambio de experiencias recíproco entre mujeres, donde se establece la confianza y el apoyo mutuo. Comparten que, las relaciones de sororidad que se establecen entre mujeres mayores contribuyen a resignificar sus propias experiencias de envejecimiento (Pérez, et.al, 2018), ilustrando cómo desde su asociatividad, también se agencia el valor contra hegemónico del apoyo mutuo, sustentado en el reconocimiento de la diversidad:

"Nuestro grupo, es muy potente (...)Ser parte de las bordadoras es pertenecer a un clan (...) Juntas nos apoyamos y sostenemos las unas a las otras y vamos proyectando el devenir con mayor esperanza (...) En esta etapa, el futuro es más corto, y va quedando menos tiempo (...) consideramos esencial, destacar lo bello que cada una tiene y respetarnos en nuestra humanidad, aceptándonos tal cuál somos y acogiéndonos" (Bordadoras, 2021, p.6).

Las Bordadoras proponen un desplazamiento del agenciamiento hacia un "nosotras" que permite reafirmar la capacidad de resistencia y aporte al desarrollo del grupo, proyectándose en torno a objetivos y motivaciones comunes. Así, este primer bordado -en colectivo- revela un tránsito que va desde el reconocimiento de la agencia individual hacia el espacio comunitario, contribuyendo a tensionar los significados asociados a la vivencia de una vejez hegemónica androcéntrica, individual y restrictiva. En esta perspectiva, el valor político de su pertenencia "al clan" se vincula con la diversidad de modos de envejecer, permitiéndoles levantar algunos hilos para "reinventarse" y sostenerse "unas a otras". Y, en este contexto, el reconocimiento de su heterogeneidad en el grupo aporta a ampliar los estrechos límites con los que el patriarcado ha definido y representado el ciclo vital de las mujeres y como éste las ha caracterizado. Así, el ser viejas en colectividad, les permite pensar en un futuro con más esperanza y cercanía, destacando con ello la importancia de la dimensión espiritual que se reviste en este bordado. 


\section{Resistir a la cotidianeidad pandémica}

"La pandemia del covid19 calo hondo en nuestras vidas, pero no todo ha sido complicado o deprimente, también ha tenido cosas positivas (...) El estar en casa, nos facilitó el explorar diferentes ofertas virtuales (...) pudimos ampliar nuestras redes, estar más conectadas, sentirnos más útiles desde el formato virtual (...) pudimos comenzar a comunicarnos más frecuentemente con la familia a través de las videollamadas, que también alimentaron nuestro espíritu (...) Incluso en nuestras reuniones con la colectiva se han generado otras dinámicas, y tardamos más en organizarnos a través del zoom, pero lo logramos (...)pudimos aprender a disfrutar de las series y las películas con mayor frecuencia que antes. (...) Otras hemos retomado actividades que habíamos dejado suspendidas (...) ¡El año de pandemia se nos ha pasado volando!" (Bordadoras, 2021, p.4-5).

Si bien la pandemia ha tenido implicancias negativas en la vida cotidiana, la existencia de vivencias positivas como la posibilidad de explorar las redes sociales, la virtualidad y disfrutar de actividades al interior de sus hogares, es destacada por las Bordadoras (2021). En concordancia con lo planteado por la Colectiva, la evidencia suele señalar que son precisamente las mujeres mayores las que utilizan y valoran más positivamente el uso de la tecnología, como una herramienta útil que les permite informarse y mantener los vínculos con sus comunidades (Herrera, et al., 2020). Al respecto, podemos ver cómo las dimensiones tecnológica y virtual no funcionan como un mero accesorio en sus prácticas, sino que éstas se ensamblan complejamente para dar sentido a las agencias que despliegan (Haraway, 1995). Sus prácticas cotidianas pueden ser comprendidas como una forma de resistencia compleja, al enfrentar en el espacio doméstico, situaciones de subordinación que están enquistadas. Las mujeres reelaboran y negocian el poder y control que tienen de este espacio a través de prácticas discretas y silenciosas (Ramos, 2017); es en el espacio doméstico donde pueden ejercerlo, en tanto deciden, por ejemplo, qué sitios web visitar y por qué medios de comunicación informarse, exponiendo que la TV abierta, es un dispositivo de desinformación hacia la población (Bordadoras, 2021).

Los discursos oficiales de control de la población mayor y las medidas especificas sobre este grupo, se han traducido en una serie de normativas que regulan sus actividades y que las representan como frágiles y dependientes, reforzando así estereotipos edadistas (Pinazo-Hernandis, 2020). Así, se concibe la crisis sanitaria como un periodo que refuerza el sentirse mayores, y acelera el deterioro físico y emocional, donde la pérdida de contacto físico en las relaciones sociales, es la dimensión que más les afecta (Bordadoras, 2021). Principalmente la pérdida de las relaciones cara a cara, y sus vinculaciones significativas ha impactado negativamente en sus vivencias. Esto es clave, al considerar que, en la vejez, los vínculos y los "lazos femeninos" que construyen las mujeres entre sí, son una dimensión central en sus vidas (Freixas, 2002-2008). Esta situación también refleja un desplazamiento de reconocimiento intrageneracional relevante, cuando manifiestan la importancia de reconectarse entre las integrantes de la colectiva: 
"para mejorar la salud mental y salir de la pandemia debemos apoyarnos entre nosotras (...) La pandemia también influyó en que dejásemos de tener reuniones frecuentemente (...) El retomar nuestros vínculos y reunirnos, incluso solamente para acompañarnos más allá del bordar juntas puede ser un espacio de contención para compartir experiencias y lo que cada una vive (...) ayudará a salir adelante y ganarle la batalla al virus" (Bordadoras, 2021, p.3-4).

Así, disputan las narrativas hegemónicas que ubican a las personas mayores como sujetos que no proyectan un mañana volviendo constantemente al pasado sin considerar el futuro (Villar y Serrat, 2015). El poder y control sobre su salud emocional se erige como un pilar para mantenerse a flote, en el cuál el enfocarse y proyectar el término de la pandemia junto al apoyo mutuo resultan centrales. Así, una aproximación a la agencia de las mujeres mayores desde sus prácticas cotidianas (Wray, 2004; 2007) permite reconocer que no son individuas pasivas sobre los cuáles se erigen una serie de disposiciones sociales, sino que son agentes que toman decisiones en sus vidas permanentemente y que, muchas de estás, impactan en su bienestar como en el de sus familias/comunidades. Igualmente, la pandemia emerge como hito transitorio, dando cuenta que la situación sanitaria va a terminar y se podrá retomar parte de la vida que quedó suspendida (Bordadoras, 2021). Esta demarcación temporal permite proyectarse, en un futuro postpandemia desde el cuál planifican continuar actuando. Y esta visualización y proyección, también se narra y borda como una construcción colectiva:

"Tenemos la convicción que esta situación de crisis sanitaria va a terminar y que podremos retomar parte de la vida que dejamos atrás. (...) hemos sido mujeres luchadoras que hemos enfrentado situaciones mucho más complejas y terribles, como fue la misma dictadura de Pinochet (...) contamos con una fortaleza y fuerza interior que nos va a ayudar a salir adelante (Bordadoras, 2021, p.3).

La reconfiguración de la cotidianeidad se constituye en su narrativa en una salida posible, asumiendo que la vida continuará después de la pandemia. Y en este contexto, la remembranza que realizan en relación a sus biografías y el haber enfrentado la dictadura, se constituye en un recurso -un antecedente- que las distingue de otras mujeres de su generación. Así, cobra sentido su compromiso y quehacer político-activista, restableciéndose como una fortaleza que da sentido y articula su agenciamiento actual como un segundo bordado.

\section{Producir más vejeces activistas}

"Al analizar la política de vejez en Chile nos sentimos agredidas y burladas, pues despliegan una serie de mentiras y falsas promesas dirigidas a las personas mayores que no representan ninguna acción concreta en favor de nosotros. En Chile, los adultos mayores somos un grupo marginado socialmente (...) la vejez se vive en condiciones de pobreza y precariedad, de abandono por parte de las políticas públicas y las instituciones sociales y con la pandemia esto quedó en evidencia (...) Existe una falta de reconocimiento de la diversidad de personas mayores, y de sus necesidades, lo que gatilla en que las acciones de la política sean mínimas y se centren en un grupo reducido (no representativo) orientándose a una participación acrítica desde la entretención y recreación. De esta forma la política no es integral y no incorpora las necesidades y motivaciones de los/las mayores. A su vez, las personas mayores son consideradasimproductivas, yqueyano aportansocialmente" (Bordadoras, 2021, p.4-5) 
La panorámica que nos presentan las Bordadoras en este fragmento contrasta fuertemente con la representación hegemónica de las personas mayores que se presenta en la literatura, en términos de su escasa incidencia social y compromiso político (lthurburu, 2014). Desde su voz emerge una crítica sólida y contundente respecto de la real incidencia de la política de envejecimiento en Chile, desarrollando argumentaciones que dan cuenta de su posicionamiento ideológico y adhesión valórica. En este sentido, por una parte, se reconocen agredidas, burladas, engañadas y, por otra, revelan el abandono creciente en que viven las personas mayores en el país, enfatizando -desde una perspectiva crítica- la reducción, estigmatización e instrumentalización que experimentan desde las políticas e instituciones públicas. Así, se describe el carácter homogenizador de la política de vejez, que no da cabida a los distintos modos de envejecer y que tampoco asume una responsabilidad en torno a las condiciones estructurales de exclusión de este grupo, lo cual se evidencia con mayor potencia en este contexto de pandemia.

Este escenario también les permite avanzar declarativamente en una denuncia que apela a su posición interseccional en la sociedad, pues las acciones del Estado lejos de contribuir al reconocimiento de su diversidad e incidencia política como cuerpo social, las posiciona como agentes improductivos y acríticos, reduciendo su participación a las esferas del entretenimiento y recreación. En afinidad con este análisis, Zubero (2018) ha indicado que, por lo general, las políticas de vejez, incentivan la participación social, desde una perspectiva recreativa pero despolitizada, tal cómo lo han propuesto las propias Bordadoras.

Esta representación, coincide con una lectura y fomento de la agencia política en términos androcéntricos y hegemónicos, es decir, que es (y puede ser) principalmente ejecutada por un hombre joven, blanco, en un espacio público tradicional, etc. (Wray, 2007). Por el contrario, una concepción más amplia de la agencia, como posibilidad de transformación y actuación -como hemos descrito anteriormente- podría ofrecer mayores elementos para robustecer la comprensión de la agencia de las mujeres mayores en el Chile contemporáneo. Y, en este sentido, sus planteamientos concuerdan con la necesidad de tensionar el modelo neoliberal autoritario que produce políticas públicas en el país y que no avanzan hacia el respeto y la aceptación de los diversos modos de envejecer, ni al reconocimiento y dignidad de las personas mayores (Mazzucchelli, 2019). Así, las Bordadoras problematizan y reflexionan en torno a sus causas, mostrando cómo la implantación del modelo es fundamento de la subvaloración y representación negativa de las personas mayores, evidenciando también los efectos negativos que se desplazan a otros grupos marginados de la sociedad chilena actual:

"Consideramos que el sistema neoliberal influye en las relaciones sociales y en que se considere a los/las mayores como personas que no aportan socialmente. Existe un desinterés por generar acciones que garanticen la dignidad y seguridad de las personas cuando envejecemos. (...) vivimos en una sociedad de consumo donde se exacerba el valor de la productividad y lo económico, pasando las personas mayores al jubilar, a ser consideradas no contribuyentes sociales, improductivos y por ende desechables. El neoliberalismo tiene un desprecio por el ser humano y lo que le importa es el enriquecimiento de unos pocos (...) Esta situación no solo afecta a los/las mayores sino a toda la población y es una herencia de la dictadura. Así, vemos que 
afecta a los niños/as a los pueblos originarios, a las minorías sexuales etc., y creemos que mientras no se cambie la constitución y el sistema económico y social que regula a Chile, no podremos avanzar a una sociedad más inclusiva con todas las edades y con todas las personas" (Bordadoras, 2021, p. 5).

Esta propuesta representa claramente el punto de vista político y compromiso social de las Bordadoras, evidenciando su posición de resistencia frente a la implantación del modelo neoliberal desde los tiempos de la dictadura en Chile y que hoy se actualiza en sus anhelos reformistas. Así, su agencia no solo da cuenta de su acción política en la vejez, y el ejercicio de prácticas de resistencia que cuestionan el orden social -dónde los márgenes (la vejez) emergen como lugares de resistencia (Hooks, 1984)-, sino que ofrecen la posibilidad de actuación como mediadoras intergeneracionales para construir y dotar de un nuevo sentido los procesos de memoria y justicia social en Chile. De esta manera, proporcionan claves para entender por qué un número importante de personas mayores en Chile no participa:

"Creemos que el sistema neoliberal y la herencia de la dictadura se impregnó en nuestra subjetividad a nivel social, y ha condicionado nuestras prácticas. Es por ello, que tenemos a adultos mayores que no participan, o se consideran apolíticos porque desde sus trayectorias y recuerdos del pasado prefieren mantenerse al margen, en silencio y no enfrentar al sistema social por temor a lo vivido. También tenemos a las otras generaciones que no han sido educadas desde un apoyo y reconocimiento a la vejez, lo que hace que no tengan una valoración y respeto por las personas mayores. En este sentido, deberíamos avanzar hacia un cambio cultural que reconozca el envejecimiento como un proceso natural en la vida, y aprenda a respetar y convivir con los mayores, aprendiendo de sus legados. Esperamos ver los frutos de la revuelta del 18 de octubre, y poder avanzar en cambiar este modelo perverso que nos condiciona y deshumaniza" (Bordadoras, 2021, p. 5-6).

Este planteamiento podría vincularse a lo que Isabel Piper (2015) llama "recordar callando", como una posición argumentativa donde mediante un silencio activo -como forma de acción social-, se omite hablar del pasado y de los hechos violentos. Esta propuesta podría contribuir a comprender lo que señalan las Bordadoras, respecto a las personas mayores que deciden marginarse de los asuntos políticos e invita a reflexionar en la continuidad que sí ha tenido, el activismo en estas mujeres, pese al pasado violento y dictatorial en el que se desarrollaron como generación y, más aún, condicionadas por género y las otras discriminaciones interseccionales que han enfrentado al ser mujeres. En este contexto, desarrollan un ejercicio de identificación grupal, que las hace interpelar a "otras" personas mayores que acríticamente aceptan las representaciones hegemónicas de la vejez y se conforman con un trato asistencial. Este saber producido resulta muy interesante, ya que ofrece una distinción entre aquellos que serían capaces de confrontar el sistema y los valores promovidos desde la política de vejez y aquellos que serían receptores acríticos de ésta. Y particularmente, la descripción de sus trayectorias de acción política desplegadas en su participación en la Colectiva, se constituye en un espacio para dar continuidad, hoy, a su lucha política:

"En la Colectiva Bordadoras por la Memoria, representamos a través de nuestras obras -bordados, tapices, exposiciones- nuestra acción política por la justicia social y los Derechos Humanos. Nosotras no bordamos por entretención, jjuntas creamos memoria y nos sentimos útiles! (...) permanecemos fieles a nuestros valores, a nuestra historia, comprometidas socialmente con los procesos de memoria y con contribuir a la transformación de un Chile más justo, para las nuevas generaciones" (Bordadoras, 2021, p. 6). 
Desde la conformación grupal de un "nosotras", este último fragmento demarca límites entre su actuación y la de otras mujeres mayores. Esta identificación puede ser comprendida, en tanto en sus trayectorias activistas comparten la lucha contra la dictadura, las tareas de defensa a los Derechos Humanos y la necesidad de hablar por ellas mismas y reconstruir su aporte a la historia (Sapriza, 2009). Retomando los planteamientos de Donna Haraway (1996) proponemos dejar de pensar en términos fijos e identitarios la agencia de las mujeres mayores y transitar hacia su comprensión como intermediaria; como mediación en movimiento, es decir, una agencia en constante proceso de construcción y deconstrucción, que se va desplegando y significando desde los márgenes. Este tercer bordado pone en evidencia las trayectorias de acción política de las mujeres mayores, y cómo éstas se resignifican, renuevan, desafían y proyectan en su vejez.

\section{Conclusiones}

La pandemia por covid19, ha implicado un profundo impacto en la vida de las personas mayores (Pinazo-Hernandis, 2020). No obstante, la producción académica frente a la crisis sanitaria se ha centrado en la población mayor como grupo de riesgo y en el impacto negativo en sus niveles de salud y bienestar, lo que podría estar reproduciendo una mirada que los ubica como sujetos de asistencia y protección, por sobre sujetos de derecho (Yuni, 2019). En este sentido, la literatura suele describir que en la vejez existen amenazas al sentido de continuidad personal, relacionados con las pérdidas y adaptaciones que deben afrontar las personas mayores (Villar y Serrat, 2015) señalando que, el contexto de pandemia, éstas se han acrecentado (Pinazo-Hernandis, 2020). Si bien este fenómeno no puede obviarse; de modo alternativo, el texto narrativo de las Bordadoras expone la agencia y resistencia ejercida en torno al confinamiento sanitario, por medio de la innovación en sus rutinas, formas de comunicación y resolución de problemas asociados a los formatos remotos. Así, las mujeres mayores desarrollan nuevas formas de gestionar los tiempos cotidianos, donde su agencia da cuenta de estrategias que no suelen ser esperadas -al considerarlas receptoras pasivas sin autonomía ni autodeterminación- confrontando así, su situación de sumisión (Charpentier y Quéniart, 2017).

En este trabajo hemos utilizado la categoría mujeres mayores, y no mujer mayor, para referirnos a la diversidad de experiencias y vejeces, que habitan esta etapa vital. No obstante, siguiendo lo planteado por Fuss (1989), la categoría mujeres sigue ocupando una unidad lingüística que refiere a la heterogeneidad, aunque semánticamente expresa una colectividad, aportándonos al diálogo que hemos esbozado en el bordado de esta investigación. Así las mujeres de la colectiva representan un nosotras (un colectivo), pero, tanto entre ellas, como fuera de su agrupación, encontramos un importante testimonio de la diversidad de experiencias y modos de envejecer siendo mayores. El reconocimiento de esta amplitud en la categoría mujeres mayores, nos aporta a ampliar los estrechos límites con los que el patriarcado ha definido y representado el ciclo vital de las mujeres y como éste las ha caracterizado (Freixas, 2002; 2008). 
En general, la representación hegemónica de las mujeres mayores las ubica como individuos al margen de los espacios de visibilidad y poder (Freixas, 2008). Particularmente las Bordadoras, ofrecen una crítica explícita y rotunda a la política de envejecimiento en Chile, desarrollando argumentaciones que dan cuenta de su posicionamiento ideológico y adhesión valórica. De esta manera, cuestionan la política, en tanto margina y abandona a la población mayor de la cuál ellas mismas son parte. Desafían a su vez, los planteamientos que reducen el involucramiento y compromiso social de las personas mayores y corrigen la representación de éstas como individuos desinformados y sin opinión. También señalan que existiría una falta de reconocimiento de su diversidad, lo que se traduce en que las acciones de la política se centren en un grupo reducido (no representativo) e incentiven solo actividades asistenciales y recreativas, en desmedro de las acciones críticas (Bordadoras, 2021).

Al respecto, algunos estudios han descrito que la participación en la vejez, puede verse aminorada por los cambios y limitaciones físicas y funcionales más proclives de presentarse en esta etapa (Raymond, et.al 2014). Contrariamente, la Colectiva muestra que ni los cambios orgánicos funcionales experimentados en su envejecer, ni tampoco el contexto de confinamiento sanitario, mermaron su participación y el desarrollo de su agencia política. Y al respecto señalan que, con el confinamiento, se han generado otras dinámicas en torno al funcionamiento de la agrupación, aprendiendo a organizarse de otras maneras y superando así las dificultades (Bordadoras, 2021). Esta situación invita a reflexionar en torno a la diada autonomía-dependencia, en la que suele catalogarse a la población mayor, ya que frecuentemente la participación se reduce a quienes disponen mayor autonomía funcional y, por ende, se excluye a las personas "frágiles" o que requieren apoyo en sus actividades (Subirats, 2018). La reducción de la autonomía a la autonomía funcional, limita la comprensión del proceso de envejecimiento entendido como un continuo natural en el desarrollo de las personas y donde es esperable que en algún momento se requiera del apoyo de otros/as. En este sentido, vislumbramos un gran desafío; el resignificar el "necesitar de otros/as" como un proceso relacional de interdependencia, propio de la vida misma y no cómo un problema únicamente asociado a la vejez. Este cambio de mirada permite avanzar desde la lógica productivista-capacitista, que bien mencionaron las Bordadoras como condicionante de los vínculos que establecemos, hacia una lógica que valore y respete a las personas, independiente de su edad y condición.

El análisis de la Colectiva da cuenta de la importancia del rol del Estado en la ejecución de una política pública mayormente inclusiva. Del mismo modo, dan un paso más allá, sugiriendo que el problema también radica en el ámbito cultural y simbólico en torno a las representaciones de la vejez, donde como sociedad también aceptaríamos los lineamientos programáticos, siendo complacientes con el sistema neoliberal. En este sentido, desafían las construcciones convencionales sobre las personas mayores como acríticas y despolitizadas, interpelando a su propia generación, al indicar que un amplio número de personas mayores validan el trato e imagen que construyen de ellos sin enfrentan el lugar marginal en el cuál se les ubica (Bordadoras, 2021). 


\section{Agradecimientos}

Agradecemos a la Colectiva Bordadoras por la Memoria por su participación en la investigación y por su autoría en la Producción Narrativa compartida en este trabajo.

Este trabajo fue apoyado por la Agencia Nacional de Investigación y Desarrollo de Chile (ANID/Doctorado Nacional/2018-21 180106), y es producto de la Tesis Doctoral de la primera autora.

\section{Bibliografía}

Aguierre, R. Y Scavino, S. (2018). Vejeces de las mujeres: Desafíos para la igualdad de género y la justicia social en Uruguay. Uruguay: Doble Clic Editoras.

Amorós, C. (2001). Feminismo, Igualdad y Diferencia. México: Programa Universitario de Estudios de Género, Coordinación de Humanidades, UNAM.

Akram, H. (2020). El Estallido. ¿ Por qué? ¿Hacia dónde? Santiago de Chile: elDesoncierto.

Balasch, M. Y Montenegro, M. (2003). Una propuesta metodológica desde la epistemología de los conocimientos situados: Las producciones narrativas. Encuentros en Psicología Social, 1 (3), 44-48. Recuperado de: https://www. academia.edu/762651/Una_propuesta_metodol\%C3\%B3gica_desde_la_ epistemolog\%C3\%ADa_de_los_conocimientos_situados_Las_producciones_ narrativas

Bordadoras (2021). Producción Narrativa. "Vejeces en resistencia" (Tesis Doctoral). Viejas y activistas. La deconstrucción de la vejez hegemónica de la agencia y asociatividad.

Caro, P. (2017). El lugar social de la vejez en territorios rurales de Aconcagua, un análisis de género, Polis, 48, 1-18. Recuperado de: http://journals.openedition.org/polis/12679

Charpentier, M., \& Quéniart, A. (2017). Aging experiences of older immigrant women in Québec (Canada): From deskilling to liberation. Journal of Women and Aging, 29(5), 437-447.doi: https://doi.org/10.1080/08952841.2016.1213111

Chazan, M. (2016). Settler solidarities as praxis: understanding 'granny activism' beyond the highly-visible. Social Movement Studies, 15(5), 457-470, doi: https://doi.org/10.1080/14742837.2016.1187594

Comisión Económica para América Latina y el Caribe (CEPAL). (2019). La autonomía de las mujeres en escenarios económicos cambiantes. Recuperado de: https://www.cepal.org/sites/default/files/publication/files/45032/S1900723_ es.pdf

Contreras, T., Guajardo, S., Y Zarzuri, R. (2005). Identidad, participación e hitos de resistencia juvenil en el Chile contemporáneo. Chile, Centro de Estudios Socioculturales (CESC).

Datan, N. (1989). Aging Women: The Silent Majority. Women's Studies Quarterly, 17(1/2), 12-19. Recuperado de: http://www.jstor.org/stable/40003974

Gerópolis. (2020). Diario íntimo de Chile. Letras mayores en tiempos de pandemia. Universidad de Valparaíso: Valparaíso.

Dourado, S. P. da C. (2020). A pandemia de COVID-19 e a conversão de idosos em "grupo de risco". Cadernos De Campo (São Paulo - 1991), 29(supl), 153162. doi:https://doi.org/10.11606/issn.2316-9133.v29isuplp153-162

Ema, J.E. (2004). Del sujeto a la agencia (a través de lo político). Athenea Digital, 6(5), 1-24. https://doi.org/10.5565/rev/athenead/v1n5.114

Fuss, D. (1989). Essentially Speaking. Feminism, Nature and Difference. Londres, Routledge.

Freixas, A. (2002). Las mujeres queremos ser mayores y poder parecerlo. En V. Maquieira (Ed.), Mujeres mayores en el siglo XXI: de la invisibilidad al protagonismo. Madrid: Ministerio de Trabajo y Asuntos Sociales.

Freixas, A. (2008). La vida de las mujeres mayores a la luz de la investigación gerontológica feminista. Anuario de Psicología, 39(1), 41-57. doi: https://doi.or- 


\section{$\mathrm{g} / 10.1344 / \% 25 \mathrm{x}$}

Gergen, K., Y Gergen, M. (1983). Narratives of the self. En Sarbin, T., Scheibe, K. (Eds.), Studies in social identity (pp. 225-273). New York: Praeger.

Gómez-Rubio, C. (2019). Vejez y cuidados. Eso que le pasa a otros(as). Discursos experiencias autogestionadas en personas mayores de Santiago de Chile. (Tesis doctoral). Universidad Autónoma de Barcelona, España.

Gonzálvez, H., Y Lube, M. (2020). Women and aging in social research (1950-2018). Revista Estudos Feministas, 28(1), 1-14. doi: https://doi.org/10.1590/1806-95842020v28n158497

Gonzálvez, H., Lube, M., Ramírez, A. y Cano, C. (2019). El club como trinchera. Una etnografía sobre cuidados comunitarios entre mujeres mayores en Independencia (Chile). Rev. antropol. soc. 28(1), 137-166.doi: http://dx.doi. org/10.5209/RASO.63770

Haraway, D. (1995). Ciencia, cyborgs y mujeres. La reinvención de la naturaleza. España: Ediciones Cátedra.

Haraway, D. (1999). Las promesas de los monstruos: una política regeneradora para otros inapropiados/bles. Política y Sociedad, 30, 121-163. Recuperado de: https://revistas.ucm.es/index.php/POSO/article/view/POSO9999130121A

Herrera, M., Fernández, M. Y Rojas, M. (2020). Chile Y Sus Mayores. Resultados V Encuesta Nacional Calidad de Vida en la Vejez 2019 UC-Caja Los Andes. Santiago: Pontificia Universidad Católica de Chile Y Caja Los Andes.

Huenchuán, S. (Ed.). (2018). Envejecimiento, personas mayores y agenda 2030 para el desarrollo sostenible. Perspectiva regional y de derechos humanos. Santiago de Chile: Comisión Económica para América Latina y el Caribe (CEPAL).

Hooks, B. (1984). Feminist Theory: From Margin to Center. Boston, South End Press.

Inthurburu, T. (2014). Personas mayores y políticas activas con perspectiva de género en la Argentina. En Huenchuán, S. Y Rodiguez, R. (Eds.), Autonomía y dignidad en la vejez: teoría y práctica en políticas de derechos de las personas mayores. Ciudad de México: CEPAL.

Love, P. (Ed.). (2018), Envejecimiento. Análisis de temas de actualidad, Esenciales OCDE, OECD Publishing, París. doi: http://dx.doi.org/10.1787/97892642881 19-es

Mazzucchelli, N. (2019). Envejecimiento Positivo para Chile: ¿ Una vejez sin Estado? Revista Kairós: Gerontologia, 22 (3), 25-42. https://doi.org/10.23925/2176-901x. 2019v22i3p25-42

Ministerio de salud de Chile (MINSAL). (2020). Disponible en: http://www.senama. gob.cl/storage/docs/MEDIDAS_PARA_LAS_PERSONAS_MAYORES_EN_CONTEXTO COVID.pdf

Moya, M. (2013). Genealogía de una vejez no anunciada: biopolítica de los cuerpos envejecidos o del advenimiento de la gerontogubernamentalidad. Polis, 36, 1-17.Recuperado de: http://journals.openedition.org/polis/9597

OMS (2020). Preguntas y respuestas sobre la enfermedad por coronavirus (COVID-19). Organización Mundial de la Salud. Consultado el 20 de Mayo de 2021 desde: https://www.who.int/es/emergencies/diseases/novel-coronavirus-2019/advice-for-public/q-acoronaviruses

Osorio-Parraguez, P., Jorquera, P. y Araya, M. (2021). Vejez y vida cotidiana en tiempos de pandemia: estrategias, decisiones y cambios. Horizontes Antropológicos, 59, 227-243. doi: http://dx.doi.org/10.1590/S0104-71832021000100012

Pinazo-Hernandis, S. (2020). Impacto psicosocial de la COVID-19 en las personas mayores: problemas y retos. Revista española de geriatría y gerontología, 55(5), 249-252. doi:https://doi.org/10.1016/j.regg.2020.05.006

Ramos, M. (2017). Envejecer siendo mujer. Dificultades, oportunidades y retos. Barcelona, España: Edicions Bellaterra.

Raymond, É., Grenier, A., Hanley, J. (2014). Community participation of older adults with disabilities. Journal of Community \& Applied Social Psychology, 24 (1), 5062. doi:http://dx.doi.org/10.1002/casp.2173

Sampedro, P. (2015). Sexualidad y envejecimiento. En Freixas, A. (Edit.) Abuelas, madres, hijas. La transmisión sociocultural del arte de envejecer (57-66). Barcelona: Icaria.

Sapriza, G. (2009). Memorias de mujeres en el relato de la dictadura (Uruguay, 1973-1985). Violencia / cárcel / exilio. DEP. Deportate, esuli, profughe. 11, 6480. Recuperado de:https://www.unive.it/pag/fileadmin/user_upload/diparti- 
menti/DSLCC/documenti/DEP/numeri/n1 1/07_Dep_11_2009Sapriza.pdf

Schöngut, N., y Pujol, J. (2015). Relatos metodológicos: Difractando experiencias narrativas de investigación. Forum Qualitative Research Sozialforschung, 16(2), 44-48. Recuperado de: https://ddd.uab.cat/record/132224

Subirats, J. (2018). Una concepción del envejecimiento abierta e inclusiva. Edad y ciudadanía / An open and inclusive ageing concept. Age and citizenship. Aula Abierta, 47(1), 13-20.doi: https://doi.org/10.1781 1/rifie.47.1.2018.13-20

Troncoso, L. y Piper, I (2015). Género y memoria: articulaciones críticas y feministas. Athenea Digital, 15(1), 65-90. doi:http://dx.doi.org/10.5565/rev/athenea.1231

Valdés, T. (1986). El movimiento poblacional: la recomposición de las solidaridades sociales. Santiago de Chile: FLACSO.

Wray, S. (2007). To what extent do ethnic and cultural diversity influence women's experiences of growing older? En A. Tiihonen and I. Syren (Eds.), Ikaantyminen ja Sukupuoli [Age and gender] (pp. 1-13). Helsinki, Finland: The Age Institute. Recuperado de http://eprints.hud. ac.uk/4734/1/WrayWhat.pdf

Wray, S. (2004). What constitutes agency and empowerment for women in later life? Sociological Review, 52(1), 22-38. https://doi.org/10.1111\%2Fj.1467954X.2 004.00440.x

Zubero, I. (2018). Envejecimiento activo y participación política. Aula abierta, 47(1). 21-28. doi:https://doi.org/10.17811/rifie.47.1.2018.21-28

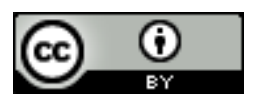

Este es un artículo de acceso abierto bajo licencia Creative Commons Reconocimiento 4.0 Internacional 